\title{
Temperature during operations on the aortic arch: How low should we go?
}

\author{
Nicholas T. Kouchoukos, MD
}

\author{
From the Division of Cardiovascular and Thoracic Surgery, Missouri Baptist Medical Center, BJC HealthCare, St \\ Louis, Mo. \\ Disclosures: Author has nothing to disclose with regard to commercial support. \\ Received for publication Dec 13, 2016; accepted for publication Dec 19, 2016; available ahead of print Jan 11, \\ 2017. \\ Address for reprints: Nicholas T. Kouchoukos, MD, Division of Cardiac Thoracic and Vascular Surgery, $3009 \mathrm{~N}$ \\ Ballas Rd, Suite 360C, St Louis, MO 63131 (E-mail: ntkouch@aol.com). \\ J Thorac Cardiovasc Surg 2017;153:765-6 \\ $0022-5223 / \$ 36.00$ \\ Copyright (c) 2016 by The American Association for Thoracic Surgery \\ http://dx.doi.org/10.1016/j.jtcvs.2016.12.019
}

The optimal temperature at which to perform aortic arch operations that require an interval of circulatory arrest continues to be debated. There is increasing evidence that with use of antegrade brain perfusion, these procedures can be performed at higher core temperatures with outcomes that may be as good or possibly even better than those achieved with what is generally regarded as deep hypothermia $\left(\mathrm{eg}, 14^{\circ} \mathrm{C}-20^{\circ} \mathrm{C}\right) .^{1,2}$ Preventza and colleagues ${ }^{3}$ report the results of a retrospective analysis of 544 patients undergoing operations on an aortic arch requiring antegrade cerebral perfusion for more than 30 minutes, and assess the influence of varying core temperatures on outcomes. The patients were assigned to 1 of 3 categories according to the core temperature measured at the time of onset of circulatory arrest: deep, low-moderate, or high-moderate hypothermia. The cerebral perfusate temperature was essentially identical to the core temperature at the time of circulatory arrest.

In the overall analysis and in the propensity-matching analysis, which compared the deep hypothermia group with the combined moderate hypothermia groups, no significant differences in operative mortality were observed. Stroke rate was highest in the deep hypothermia group in the overall analysis, but did not achieve statistical significance in the propensity-score matching analysis. Among the subset of patients with a cerebral perfusion time $>45$ minutes $(56 \%$ of the total group), the stroke rate in the deep-hypothermia group was significantly higher than in the moderate group. However, multivariate analysis identified Type I dissection, emergent status, and prior neurologic event as other significant predictors of postoperative stroke. There were no significant differences in the prevalence of postoperative renal injury among the 3 hypothermia groups. Midterm survival was significantly better in the moderate versus the deep-hypothermia group.

Although propensity-score matching likely provides the best observational evidence for drawing conclusions from

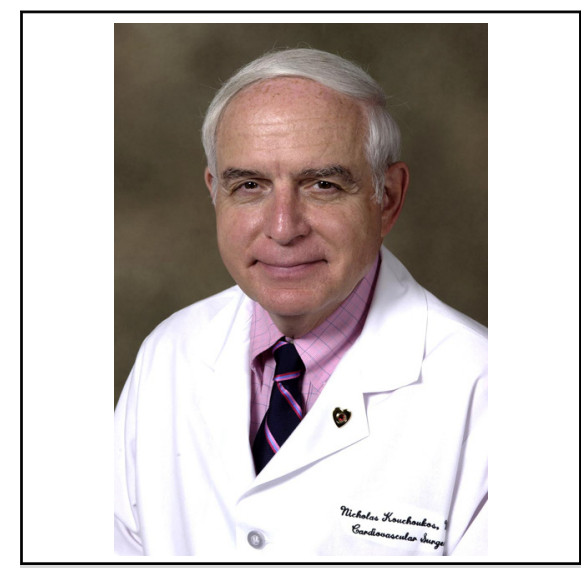

Nicholas T. Kouchoukos, MD

\section{Central Message}

Moderate hypothermia combined with antegrade brain perfusion for operations involving the aortic arch is being used with increasing frequency, but questions remain.

See Article page 767.

retrospective analyses, bias cannot be completely eliminated. Potential sources for bias in this study include a preference for low-moderate hypothermia among the 3 options (48\% of cases); bilateral over unilateral cerebral perfusion $(68 \%$ vs $32 \%)$, particularly in cases where repair was anticipated to be more complex; greater use of low temperatures early in the study period; and possible underreporting of late deaths due to deficiencies in the Social Security Death Master Index. Year of operation was not included as a variable in the analyses, and this is an important limitation as well.

A minor, but potentially important finding was the higher rate of persistent spinal cord ischemic injury among the moderate-hypothermia patients who underwent total arch replacement $(1.4 \%$ [ 2 out of 147 patients in the lowhypothermia group], $2.3 \%$ [2 out of 88 patients in the high-hypothermia group], and no injury among the 70 patients in the deep-hypothermia group). Three of 4 patients with ischemic injury underwent an elephant trunk procedure ( 2 traditional and 1 frozen). Spinal cord injury following the elephant trunk procedure has been noted in previous studies, and higher core temperature combined with an interval of lower body ischemia is a possible contributing factor. ${ }^{4-6}$

In the title of their article, the authors ask the question: "How relevant is the influence of temperature in aortic 
arch surgery patients receiving antegrade cerebral perfusion for $>30$ minutes?" No definitive answer to this question is provided. Because the propensity-matched analyses identified no statistically significant differences in outcomes between the 3 temperature levels, but a trend toward higher stroke rate and reoperations for bleeding was seen in the deep-hypothermia group, do they believe that deep hypothermia should be abandoned? If not, when should it be used? The authors do not present their current algorithm for selection of the appropriate temperature for a specific patient based on the results of their study.

The rationale for use of deep hypothermia with or without an interval of antegrade brain perfusion for aortic arch operations continues to be challenged despite the satisfactory outcomes that have been achieved in experienced centers. ${ }^{7,8}$ Large, randomized trials comparing deep with moderate hypothermia in aortic arch surgery do not exist, and until data from such trials become available, abandonment of deep hypothermia, particularly for prolonged, complex total arch procedures, would be unwise.

\section{References}

1. Yan TD, Bannon PG, Bavaria J, Coselli JS, Elefteriades JA, Griepp RB, et al. Consensus on hypothermia in aortic arch surgery. Ann Cardiothorac Surg. 2013; 2:163-8.

2. Tian DH, Wan B, Bannon PG, Misfield MD, LeMaire SA, Kazui T, et al. A metaanalysis of deep hypothermic circulatory arrest versus moderate hypothermic circulatory arrest with selective antegrade cerebral perfusion. Ann Cardiothorac Surg. 2013;2:148-58

3. Preventza O, Coselli JS, Akvan S, Kashyap SA, Garcia A, Simpson KH, et al. The impact of temperature in aortic surgery patients receiving antegrade cerebral perfusion for $>30$ minutes: how relevant is it really? J Cardiothorac Vasc Surg. 2017; 153:767-76.

4. Cao P, DeRango P, Czerny M, Evangelista A, Fattori R, Nienaber C, et al. Systematic review of clinical outcomes in hybrid procedures for aortic arch dissections and other arch diseases. J Cardiothorac Vasc Surg. 2012;144:1286-300.

5. Leontyev S, Borger MA, Etz CD, Moz M, Seeburger J, Bakhtiary F, et al. Experience with the conventional and frozen elephant trunk technique: a singlecentre study. Euro J Cardiothorac Surg. 2013;44:1076-82.

6. Shrestha M, Beckmann E, Krueger H, Fleissner F, Kaufeld T, Koigeldiyev N, et al. The elephant trunk is freezing: the Hannover experience. J Cardiothorac Vasc Surg. 2015;149:1286-93.

7. Etz CD, Plestis KA, Kari FA, Luehr M, Bodian CA, Spielvogel D, et al. Staged repair of thoracic and thoracoabdominal aortic aneurysms using the elephant trunk technique: a consecutive series of 215 first stage and 120 complete repairs. Euro J Cardiothorac Surg. 2008;34:605-15.

8. Ziganshin BA, Rajbanshi BG, Tranquilli M, Fang H, Rizzo JA, Elefteriades JA. Straight deep hypothermic circulatory arrest for cerebral protection during aortic arch surgery: safe and effective. J Thorac Cardiovasc Surg. 2014;148:888-98. 